\title{
Charles Wiener o el disfraz de una misión lúcida
}

Charles Wiener ou les faux-semblants d'une brillante mission

Charles wiener or the disguise of a brilliant mission

\section{Pascal Riviale}

\section{OpenEdition}

Journals

Edición electrónica

URL: http://journals.openedition.org/bifea/6153

DOI: $10.4000 /$ bifea. 6153

ISSN: 2076-5827

Editor

Institut Français d'Études Andines

Edición impresa

Fecha de publicación: 1 diciembre 2003

Paginación: 539-547

ISSN: 0303-7495

Referencia electrónica

Pascal Riviale, "Charles Wiener o el disfraz de una misión lúcida », Bulletin de l'Institut français d'études andines [En línea], 32 (3) | 2003, Publicado el 08 diciembre 2003, consultado el 01 diciembre 2020. URL : http://journals.openedition.org/bifea/6153 ; DOI : https://doi.org/10.4000/bifea.6153

\section{(c) (7) $\odot$}

Les contenus du Bulletin de l'Institut français d'études andines sont mis à disposition selon les termes de la licence Creative Commons Attribution - Pas d'Utilisation Commerciale - Pas de Modification 4.0 International. 


\section{CHARLES WIENER O EL DISFRAZ DE UNA MISIÓN LÚCIDA}

Pascal RIVIALE*

\section{Resumen}

Charles Wiener fue uno de los exploradores más celebrados de su tiempo por su contribución al conocimiento del Perú prehispánico, gracias a las colecciones llevadas a Francia y a sus publicaciones. Sin embargo, esas últimas hicieron creer que él actuó solo, animado por un don milagroso para encontrar rápidamente datos y especímenes arqueológicos. Eso fue sin duda su talento mayor: su capacidad para mobilisar un número importante de actores secundarios afin de realizar su proyecto ambicioso.

Ese ejemplo vale seguramente por otros viajeros cuyas "investigaciones" fueron también idealizadas. Así aparece entonces la necesidad de relativisar su historia oficial y de tomar en cuenta un segundo término a veces difícil de determinar.

Palabras claves: Charles Wiener, Perú, siglo XIX, misiones arqueológicas.

\section{CHARLES WIENER OU LES FAUX-SEMBLANTS D'UNE BRILLANTE MISSION}

\section{Résumé}

Charles Wiener fut l'un des explorateurs les plus célébrés de son temps pour sa contribution à la connaissance du Pérou préhispanique, tant grâce aux collections rapportées en France que pour ses publications. Ces dernières ont toutefois tendance à faire croire qu'il avait agi seul, animé d'un don miraculeux pour débusquer tambour battant informations et spécimens archéologiques. Or, c'est sans doute là le principal talent de Wiener que d'avoir su mobiliser un grand nombre d'acteurs secondaires, afin de réaliser son ambitieux projet.

L'exemple donné ici s'applique certainement à d'autres voyageurs dont les “ recherches ont été également idéalisées. D'où la nécessité de relativiser leur histoire officielle et de prendre en compte un arrière-plan parfois difficile à cerner.

Mots clés : Charles Wiener, Pérou, XIXe siècle, missions archéologiques.

*Musée d'Orsay, 62, rue de Lille 75007 Paris, France. E-mail: pascal.riviale@ musee-orsay.fr 


\section{CHARLES WIENER OR THE DISGUISE OF A BRILLIANT MISSION}

\section{Abstract}

Charles Wiener was one of the most famous explorators of his time for his contribution to the knowledge of prehispanical Peru. Thanks to the collections he brought to France, as well as to his publications. The lectors of his accounts could believe Wiener operated alone, thanks to a miracle gift which allowed him to discover archaeologial datas and collections with a stunning rapidity. It was maybe his major talent: his capacity to mobilize a lot of persons with the purpose to realize his ambitious project.

This exemple can be applied to other travellers whose "investigations" have been idealised too. It should be necesary to keep some distance with their official history and to take account a background sometimes difficult to see.

Key words: Charles Wiener, Peru, XIX ${ }^{\text {th }}$ century, Archaeological Missions.

Se trata acá de ver la contribución de los viajeros al desarrollo de las ciencias (en lo que concierne los avances teóricos o el empleo de nuevas prácticas científicas). Pero no habría que caer en la hagiografía. Así que debemos interrogarnos sobre la fiabilidad de las imágenes que nos han transmitido tradiciones bien establecidas. De este modo hemos visto aparecer, a través de las publicaciones populares del siglo XIX (1), el personaje del explorador heroíco, pionero — y a veces mártir — de la ciencia, haciendo su trabajo en solitario bajo las inclemencias, a veces sufriendo hambre y sed, animado por un objetivo único: descubrir tierras o culturas desconocidas y hacerlas conocer al mundo occidental con el riesgo de su vida. Es esta imagen, aquí presentada de manera por supuesto caricatural, que me propongo relativizar, a través del caso de un viajero bien conocido: Charles Wiener.

\section{CIVILIZACIONES DESCONOCIDAS}

Cuando, en 1875, Charles Wiener fue encargado de una misión científica en el Perú y en Bolivia, las culturas indígenas de la América prehispánica quedaban en su mayor parte desconocidas. Solo las más grandes civilizaciones eran conocidas por unos pocos eruditos, a través de unos cuantos estudios de campo y sobretodo a través de crónicas de la Conquista o del periodo colonial o de obras de compendio a menudo poco documentadas.

En realidad el interés para los pueblos americanos formaba parte de una problemática mucho más amplia sobre el hombre, sus orígenes, su diversidad física y cultural (con la cuestión de la unidad o de la pluralidad de las especies humanas). Los viajes de circumnavegación y las exploraciones por tierra del siglo XVIII y del inicio del siglo XIX habían revelado la existencia de unos seres extraños (en África negra, en

(1) Principalmente revistas culturales o de viaje muy famosas por sus grabados como Le Tour du Monde, L'Illustration o Le Journal des Voyages. 
el interior del continente americano y las islas del océano Pacífico) que no se sabía dónde ubicarlos en las clasificaciones tradicionales y que provocaron muchas preguntas entre los sabios europeos. Por ejemplo, estos hombres salvajes ¿deberían clasificarse como vestigios de las primeras etapas de la evolución humana? ¿Se podía racionalmente reconocer a estos seres obviamente salvajes una comunidad de origen con las poblaciones más “desarrolladas”? Más bien ¿no se debía admitir una pluralidad de las especies humanas, así como una jerarquización de las razas y de los pueblos? Es así, que se multiplicaron con esa problemática, en la primera mitad del siglo XIX, los intentos de clasificación de la razas humanas, seguidos por un amplio debate entre los antropólogos sobre esta cuestión de la unidad o de la pluralidad de las especies humanas. El hecho que el continente americano hubiese quedado aislado del Viejo mundo hasta Colón no podía hacer menos que aumentar el misterio a propósito del origen de sus poblaciones indígenas (2). Por otro lado, ¿cómo se debía interpretar la existencia en el Nuevo Mundo de civilizaciones ya desarolladas (como los aztecas, los mayas o los incas), mientras que el resto del continente era considerado como primitivo? Este enigma preocupaba no solamente los antropólogos, sino más ampliamente los sabios interesados por la historia cultural y la noción de "civilización".

El estudio de esas sociedades indígenas de las Américas tenía entonces motivos científicos esenciales, tanto para la antropología general, así como para la historia de las civilizaciones. Sin embargo, la dominación de España había limitado el ingreso de los extranjeros a sus territorios americanos durante todo el periodo colonial. Y fue solamente después de la Independencia de las republicas andinas que fue realmente posible su exploración, pero con resultados científicos que no dieron siempre buenos resultados.

Así, hasta mediados del siglo XIX, fueron pocas las grandes expediciones oficiales que pudieron realizarse. Además la arqueología, la etnología y la antropología no occupaban más que un lugar marginal en los objetivos científicos de esos viajes (como fue el caso de los Académicos Bouguer, Godin y Lacondamine en compañía de Juan y Ulloa entre 1735 y 1745, o de Joseph Dombey con Ruiz y Pavón entre 1778 y 1785, o más tarde de Alexander von Humboldt, Alcide d'Orbigny, Francis de Castelnau, Alfred et Ernest Grandidier). Algunos de ellos, como Humboldt o d'Orbigny, realizaron un trabajo importante, tanto sobre el terreno como en su trabajo de gabinete después de regresar a Francia; sus contribuciones al desarrollo en el campo de estudio americanista fueron de primer orden (mientras Humboldt initiaba una reflexión científica sobre las sociedades prehispánicas en su libro Vues des Cordillères... [1810], las investigaciones de d'Orbigny sobre Tiahuanaco en su famosa obra sobre el Hombre Americano — publicada en 1839 - permitieron el reconocimiento de la importancia cultural de las poblaciones aymaras). Otras expediciones (en particular, a mediados del siglo XIX, como las de Castelnau, Grandidier o Colpaërt) no dieron tantos resultados por lo que concierne la arqueología y la antropología andina (Riviale, 2000a: 114-136).

Para remediar la carencia de informaciones, las instituciones oficiales contaron siempre con la ayuda de voluntarios (marineros, diplomáticos, negociantes, ingenieros

(2) Sobre este tema ver por ejemplo Blanckaert, 1995; 2000: 39 y ss; Riviale, 2000b: 363-366. 
o viajeros independientes) para darles materiales de análisis. Las pocas instrucciones que escribieron los sabios (a fines del siglo XVIII y sobretodo durante el siglo XIX) para los viajeros illustran por un lado su deseo de dar consejos y orientaciones a los voluntarios en sus investigaciones de terreno. Pero, por otro lado, nos muestran también las grandes lagunas que impidieron el desarrollo de los estudios americanos (Riviale, 2000c). En efecto, estas instrucciones nos enseñan que, hasta el último cuarto del siglo XIX, no se sabía casi nada de la multiplicidad de las culturas prehispánicas en esta parte de los Andes y era todavía muy difícil para los sabios distinguir las leyendas transmitidas por las crónicas de la realidad histórica.

El conjunto de informaciones científicas (descripciones y dibujos de monumentos, planos de sitios, y sobretodo objetos arqueológicos y especímenes antropológicos) colectadas por los voluntarios a lo largo del siglo XIX fue muy importante (3). Sin embargo, el uso de estas colecciones e informaciones se quedó bastante limitado, por una parte por la dispersión de las colecciones en el territorio y por otra, por falta de una institución científica que fuera capaz de coordinar un trabajo de investigación (Riviale, 2000a).

Sin embargo y aunque este trabajo de colecta fuese desorganizado, tenemos que apuntar que, a partir de la mitad del siglo XIX, con el desarrollo de las ciencias etnográficas y antropólogicas, la actividad americanista se hizo más amplia. Además del número creciente de objetos arqueológicos llevados a Francia que contribuyeron al desarrollo de una cierta curiosidad acerca de esos testimonios de culturas extinguidas, varios eventos favorecieron la institucionalización del americanismo. Lo atestiguan, por ejemplo, la creación de un "museo americano" en el Louvre en 1850, o la fundación de la Société d'Ethnographie orientale et américaine en 1859. La intervención francesa en México entre 1862 y 1867 contribuyó igualmente a desarrollar esta actividad americanista. Por fin, el evento mayor de este periodo fue la organización del primer congreso internacional de americanistas en Nancy en 1875.

Es en este momento importante de la evolución del campo de investigación americanista, que aparece nuestro heroe, Charles Wiener.

\section{EL VIAJE DE CHARLES WIENER Y SU REGRESO TRIUNFAL}

El 18 de junio de 1875, Charles Wiener, un joven profesor de alemán, mandaba al ministerio de Instrucción pública un proyecto de exploración arqueológica de los países andinos. Aunque desconocido del mundo científico, no era un principiante en este ambito. Discípulo del jubilado diplomático Léonce Angrand, había publicado el año precedente un Essai sur les institutions politiques, religieuses, économiques et sociales de l'empire des Incas. Probablemente aconsejado por Angrand, añadió a su candidatura un proyecto de itinerario que daba la impresión que él dominaba muy bien su tema de investigación. Un mes después, el 9 de julio, estaba encargado oficialmente de una misión arqueológica y etnográfica en el Perú y en Bolivia.

(3) Los museos franceses siguen conservando estos testimonios: existen más de 150 museos o instituciones en Francia que poseen colecciones del Nuevo Mundo. Ver Taladoire, 1992; Huerta, 2001. 
En un principio, Wiener había previsto empezar su viaje por Ecuador, continuar por el Perú y acabarlo en Bolivia. De hecho, en el último momento, modificó su itinerario y se fue a Brasil en el otoño de 1875; en Brasil se quedó unos meses antes de embarcarse para el Perú. Llegó al puerto del Callao en febrero de 1876 y ahí tomó contactos con personalidades científicas y coleccionistas peruanos. Quizas aconsejado por un negociante francés (Frédéric Quesnel, quien también coleccionaba piezas arqueológicas), Wiener hizó excavaciones intensivas en el sitio de Ancón (sitio conocido desde principios de los años 1870), primero con unos huaqueros, y algunos días después, con la ayuda de marineros franceses que puso a su disposición el almirante Périgot (jefe de la estación naval francesa del Pacífico). Lo que le permitió mandar un primer informe entusiasta al ministerio:

"He sido feliz en el Perú [...]. Hice excavaciones! He colectado como para llenar una media sala del Louvre." (4)

Después de unas semanas más de investigaciones en los alrededores de Lima, Wiener se dirigió hacia el norte por la costa hasta Trujillo (donde hizó investigaciones en Moche y Chan Chan) para seguir después dirigiéndose hasta Cajamarca, antes de seguir la ruta de la cordillera en dirección del sur. De paso estudió sitios cuyos nombres son hoy día famosos, pero que en la época eran poco conocidos de los europeos: Recuay, Chavín de Huántar, Huánuco Viejo, Vilcashuaman, Concacha, etc. (todos sitios que le había indicado Léonce Angrand, así como lo atestigua su correspondencia con el consul jubilado en el curso de su viaje) (Riviale, 2000a: 157-158). Hay que apuntar que casi en cada una de sus etapas, Wiener benefició del apoyo de compatriotas o de hacendados, felices de poder ayudar a un hombre de ciencia europeo en sus investigaciones.

En enero de 1877, llegó al Cuzco, una de las etapas mayores de su viaje en el Perú. Se quedó ahí unos meses, explorando los sitios más famosos de la región (Sacsayhuaman, San Sebastián, Pisacc, Ollantaytambo), así como otros menos conocidos. En su relación de viaje, decía haber intentado ubicar un sitio misterioso llamado "Matcho Pichu" del cual había escuchado hablar en Ollantaytambo. A mediados del año 1877, hizo también una corta exploración de las ruinas de Tiahuanaco (así como una muy discutida ascensión del Illimani), antes de irse hacia la costa del Perú, y en Lima para regresar por fin a Francia. Había hecho una estancia de 15 meses en el Perú y en Bolivia.

Los muy numerosos objetos arqueológicos y etnográficos que había mandado a Francia impresionaron mucho el ministerio de Instrucción pública, que se preguntaba lo que había que hacer de todo este material. Se decidió entonces aprovechar la próxima exposición universal que debía tenerse en París en 1878 para realizar una exposición peruana. Este proyecto fue finalmente ampliado a una exposición de las misiones científicas que acababan de realizarse, pero Wiener conservó un papel mayor, gracias a una espectacular escenografía de sus colecciones (con reconstituciones de monumentos, paisajes pintados y una impresionante pirámide de huacos en el centro de la sala).

(4) Carta al Ministro de Instrucción pública (Pachacamac, 11 de marzo de 1876), citada en Riviale, 2000a: 155. 
El explorador dio varias conferencias y publicó relaciones de sus viajes (en particular en una de las revistas entre las más famosas de la época, Le Tour du Monde). Y publicó un libro bajo el título de Pérou et Bolivie (1880). Su éxito fue coronado por una condecoración de la Legión de Honor, así como una medalla de oro de la exposición universal, antes de obtener su primer puesto diplomático en Ecuador.

El ingreso en Francia de colecciones tan numerosas favoreció seguramente la fundación de un museo de etnografía en París (cuyo proyecto existía desde algún tiempo) y contribuyó al mismo tiempo a mejorar el conocimiento de las culturas andinas prehispánicas. Los visitantes de este nuevo museo podían de esta manera ver vestigios de sociedades casi totalmente desconocidas por el gran público. Por otro lado, al mismo tiempo, los sabios obtuvieron material que les permitió hacer investigaciones más amplias. Así sucedió que los etnógrafos pudieron revisar la imagen que tenían de las sociedades indígenas y de sus culturas materiales.

Hemos visto que hacia mediados del siglo XIX no se distinguía más que dos periodos en la historia de la civilización de los Andes: un periodo aymara antiguo y un periodo inca más reciente. En los años 1870, algunos autores (como Thomas Hutchinson, Manuel González de La Rosa y Ephraim George Squier) (5) habían llamado la atención de sus colegas sobre huacos y monumentos de la costa norte del Perú que se consideraban como anteriores a los Incas. Los objetos colectados por Wiener mostraban características que podían confirmar esta impresión. Era entre otros el caso de huacos de Recuay, obsequiados al explorador por el Dr Macedo. La segunda parte del libro de Charles Wiener (parte titulada "notas arqueológicas") ilustraba, a través de numerosas láminas, esta sorprendente diversidad material.

Wiener había así querido dejar una obra científica correspondiente a su deseo de reconocimiento. Sin embargo sus contemporáneos iban poco a poco a relativizar la importancia de su contribución propia.

\section{UNA IMAGEN QUE NO COINCIDE CON LOS HECHOS}

Mientras que Wiener se iba a Ecuador para cumplir sus nuevas funciones diplomáticas (en 1879), sus colecciones se quedaron en desorden en los almacenes del futuro museo de etnografía del Trocadero. No había dejado ningún catálogo que hubiera podido permitir a los empleados del museo dar precisiones sobre la procedencia de cada objeto. Wiener parecía muy poco preocupado por este tipo de detalle, así como lo deja entender la relación de su viaje (Wiener, 1880) que contiene numerosos errores en cuanto a las indicaciones de procedencia de los objetos ilustrados.

Tengo la impresión de que si Wiener no estaba seguro de los lugares de descubrimiento de todos esos objetos, es porque fue sólo de manera muy escasa el verdadero autor de las excavaciones que pretendió haber realizado. En los años que siguieron esta "misión lúcida", fueron numerosas las personas que se quejaron

(5) Hutchinson 1873: VIII-IX ; declaración de González de La Rosa después de una ponencia de Hutchinson en el Anthroplogical Institute el 11 de noviembre de 1873 (Journal of the Anthropological Institute, 1874: 325-326); Squier, 1877: 170-192. 
descubriendo que el explorador había omitido su participación en las investigaciones. Así la mayoría de las donaciones hechas a lo largo del viaje de Wiener por compatriotas (Quesnel, Dibos, Droullion) o por coleccionistas peruanos (el Dr Macedo) que pueden identificarse a través de sus informes manuscritos, no fueron mencionados en sus publicaciones (6). Es posible que otras contribuciones hubiesen sido olvidadas de la misma manera. En su libro, Charles Wiener cuenta que cuando llegó al Cuzco fue recibido por jóvenes estudiantes del colegio de ciencias de la ciudad, pero no dice más sobre su probable verdadero papel. En su libro sobre la exploración de los ríos peruanos navegables Carlos Fry (Lima, 1889) se lamentó de la ingratitud de ciertos viajeros:

"Otros hay que omiten o callan el nombre de los que han prestado servicios importantes o suministrado datos preciosos a los viajeros extranjeros: me refiero al autor de una obra francesa que fué nuestro amigo en tiempos que le buscabamos momias y antiguedades en el Cuzco. Después hemos leido su obra; y en ella no dice quien le dio los objetos preciosos que representan las láminas que adornan sus obras ni la persona que le hizo las traducciones del quechua al español" (Fry, 1889: 110-111) (7).

Tengo la impresión que hacía aquí una alusión a Wiener. Así que se entiende mejor cómo podía descubrir tan rápido objetos en las excavaciones que pretendía haber realizado en los lugares donde apenas acababa de llegar. Estos "préstamos" podrían igualmente referirse a mapas, planos y dibujos que fueron publicados en su libro. Una última mistificación concierne las fotografías usadas para realizar los grabados que ilustran su relación de viaje. Si no es totalmente imposible que él mismo haya podido tomar algunas fotografías (pero habría que probarlo) es establecido que algunas de estas fueron compradas a fotógrafos locales: Villalba, Courret por las vistas del Perú, y Grumbkow por las de Bolivia (Majluf, 2000: notas 21 y 27; Krauskopf, 2002: 113). Hace poco Gunther Krauskopf ha publicado en La Paz un libro dedicado a tres viajeros en Bolivia (Falb, Wiener y Ber), donde demuestra cómo Wiener usó, sin citarlo, fotografías que fueron tomadas por el ingeniero Georg von Grumbkow, cambiando las referencias para ubicarlas en un contexto imaginario. Krauskopf cita la anecdota de la Virgen de Copacabana que Wiener pretendió fotografiar. En el ejemplar del libro de Wiener que perteneció a Alphons Stübel, este había apuntado "mentira, es una fotografía de Grumbkow". ¡El lo sabía muy bien porque había comprado esta misma foto al ingeniero austriaco! (Krauskopf, 2002: 113).

Seguro que Wiener no es el único que ha recurrido a tales compras. Fue probablemente una práctica común entre los viajeros que deseaban recolectar rápido material iconográfico y científico: se sabe que varios viajeros (Ber, Stübel, Falb) han comprado las mismas fotografías de Grumbkow. Para la anécdota hay que señalar que vistas idénticas han sido recién descubiertas en un museo francés (8): habían sido

(6) Por ejemplo Frédéric Quesnel obsequió cerca de 1000 piezas (tal vez más) al Estado francés en 1876 por el intermedio de Wiener quien se apropió el mérito de esta donación después de su regreso (Riviale, 2000a: 163-164). este libro.

(7) Agradezco a mi amigo Jean-Pierre Chaumeil (CNRS) quien me llamó la atención sobre

(8) Están en el museo de Remiremont. 
traídas a Francia por el ingeniero Louis Galland que residía en Pulacayo a fines del siglo XIX. Este mercado de la fotografía de la época queda todavía desconocido, pero es muy probable que estas vistas interesaban a numerosas personas, circulaban mucho (9) y que empezaban a ser objeto de una explotación tanto intelectual como comercial. Los estudios de Keith McElroy a propósito del uso de la fotografía por Squier (McElroy, 1986) y de Daniel Buck sobre la fotografía en Bolivia (Buck, 2000) lo indican muy claramente (10).

Lo que acabamos de señalar aquí por las imágenes (fotografías y dibujos) vale también para los objetos arqueológicos y etnográficos. Numerosos viajeros se aprovecharon del apoyo de eruditos y coleccionistas locales para reunir el material que ingresó a Europa o Estados Unidos (Miller, 1968; Riviale, 2000a). Los motivos de tales colaboraciones son, sin duda, varios: interés económico (lo hemos visto con el ejemplo de las fotografías), deseo de integrarse a un movimiento científico prestigioso, o bien para los eruditos, placer de encontrar un auditorio atento.

Para concluir, no quise aquí abatir nuestro amigo Wiener, pero más bien demostrar que la actividad de esos viajeros en el terreno debe ser a veces considerada con mucho cuidado. No lleva nada al mérito que él —u otros - ha tenido al cumplir su misión científica en condiciones que podían ser muy dificiles. A su manera, Wiener contribuyó ampliamente al desarrollo de las ciencias etnográficas, trayendo a Francia un material poco conocido en la época. Este evento no solo provocó nuevas preguntas acerca de la diversidad de las culturas, sino contribuyó a la decisión de crear un museo de etnografía en París (11). Si no lo hizo solo, como lo pretendía, ha tenido un papel central mobilizando numerosas buenas voluntades alrededor de un proyecto que fue el suyo. Esta acción tiene que ser interpretada de manera positiva también: es por parte en simpatía o al revés en reacción a la actividad arqueológica de esos numerosos viajeros europeos y norteamericanos que se desarrollaron en el Perú en el último tercio del siglo XIX el coleccionismo arqueológico y un interés por el estudio y la protección de un patrimonio cultural despreciado hasta entonces (12).

\section{Referencias citadas}

BLANCKAERT, C., 1995 - Le système des races. In: Le XIXe siècle. Science, politique et tradition (I. Poutrin, dir.): 21-41; París: Berger-Levrault.

BLANCKAERT, C., 2000 - Avant Adam. Les représentations analogiques de l'homme fossile dans la première moitié du XIXe siècle. In: L'Homme préhistorique. Images et imaginaire (A. \& J. Ducros, dirs.): 23-61; París: L’Harmattan.

(9) Es este fenómeno cultural que Deborah Poole llama "visual economy" (Poole, 1997).

(10) Sobre esta recolecta de documentos fotográficos por viajeros científicos ver el ejemplo muy interesante dado por López-Ocón (2000) a propósito de la Comisión española del Pacífico.

(11) La decisión fue tomada en 1878, el Musée d'Ethnographie du Trocadéro abrió sus puertas al público en 1882.

(12) Se puede observar este entonces nuevo fenómeno a través de los artículos de Ricardo Davalos y Lissón, Teodorico Olaechea o de Larrabure y Unánue (Hutchinson, 1873; Riviale, 1998). 
BUCK, D., 2000 - Early photography in Bolivia. History of photography, 24(2): 127-132.

FRY, C., 1889 - La gran región de los bosques o ríos peruanos navegables. Urubamba, Ucayali, Amazonas, Pachitea y Pacalzu. Diario de viajes y exploraciones por Carlos Fry en 1886, 1887 y 1888. Primera parte; Lima: Imprenta de Benito Gil.

HUERTA, M., 2001 - L'Amérique latine en France. Itinéraires cachés. Alma, 3: 215p. (numero especial).

HUMBOLDT, A. von, 1810 - Vues des Cordillères et monuments des peuples indigènes de l'Amérique; París: chez F. Schoell.

HUTCHINSON, Th. J., 1873 - Two years in Peru with exploration of its antiquities. 2 vol.; London: Sampton Low, Martson, Law and Searle.

HUTCHINSON, T. J., 1874 - Explorations among ancient burial grounds (chiefly on the seacost valleys) of Peru. Part 1. Journal of the Anthropological Institute of Great Britain and Ireland, III: 311-326.

KRAUSKOPF, G., 2002 - Tres viajeros europeos precientíficos en Bolivia del siglo XIX: Falb, Wiener, Ber, 144p.; La Paz: Instituto de arqueología boliviana de la Universidad San Francisco de Asis.

LÓPEZ-OCÓN, L. \& PÉREZ-MONTES, C. M. (eds.), 2000 - Marcos Jiménez de La Espada (1831-1898). Tras las sendas de un explorador, 384p.; Madrid: Consejo Superior de Investigaciones Científicas, Instituto de Historia.

MAJLUF, N., 2000 - Photographers in andean visual culture. Traces of an absent landscape. History of photography, 24(2): 91-100.

McELROY, K., 1986 - Ephraïm George Squier: photography and the illustration of peruvian antiquities. History of photography, 10(2): 99-129.

MILLER, R. R., 1968 - For science and national glory. The spanish Scientific Expedition to America, 1862-1866, 194p.; University of Oklahoma Press. 194.

ORBIGNY, A. d', 1839 - L'Homme américain; París: Pitois-Levrault.

POOLE, D., 1997 - Vision, race and modernity: a visual economy of the andean image world, 263p.; Princeton: Princeton University Press.

RIVIALE, P., 1998 - L'archéologie péruvienne et ses modèles au XIXe siècle. In: L'Amérique latine et les modèles européens (A. Lempérière, G. Lomné, F. Martinez \& D. Rolland, coords.): 275-308; París: L’Harmattan - Maison des Pays Ibériques.

RIVIALE, P., 2000a - Los viajeros franceses en busca del Perú antiguo (1821-1914), 456p.; Lima: Instituto Francés de Estudios Andinos - Pontificia Universidad Católica del Perú.

RIVIALE, P., 2000b - L'oeuvre archéologique d'Alcide d'Orbigny. In: Alcide d'Orbigny à la découverte des nouvelles républiques sud-américaines (bajo la dirección de Philippe de Laborde Pédelahore): 363-386; Biarritz: Atlantica.

RIVIALE, P., 2000c - Las instrucciones científicas francesas para el estudio del Perú prehispánico (siglos XVIII y XIX). Bulletin de l'Institut Français d'Études Andines, 29(1): 29-61.

SQUIER, E. G., 1877 - Peru: Incidents of travel and explorationin the land of the Incas, 599p.; London: Macmillan and co.

TALADOIRE, É., 1992 - Répertoire préliminaire des collections américanistes dans les musées d'Europe. Bulletin des Musées Royaux d'Art et d'Histoire, 63: 269-295.

WIENER, C., 1874 - Essai sur les institutions politiques, religieuses, économiques et sociales de l'empire des Incas; París: Maisonneuve.

WIENER, C., 1880 - Pérou et Bolivie; París: Hachette. 